\title{
Ethanolic Extract of Traditional Chinese Medicine (TCM) Gamboge Inhibits Colon Cancer via the Wnt/Beta-Catenin Signaling Pathway in an Orthotopic Mouse Model
}

\author{
WEI WANG ${ }^{1 *}$, YOURAN LI ${ }^{2 *}$, YIQI CHEN ${ }^{2}$, HONGJIN CHEN ${ }^{1}$, PING ZHU ${ }^{1}$, MINMIN XU ${ }^{2}$, \\ HAO WANG $^{2}$, MINNA WU ${ }^{1}$, ZHIJIAN YANG ${ }^{3}$, ROBERT M. HOFFMAN ${ }^{3,4}$ and YUNFEI GU ${ }^{1}$ \\ ${ }^{1}$ Nanjing University of Chinese Medicine, Nanjing, P.R. China; \\ ${ }^{2}$ Department of Colorectal Surgery, Jiangsu Province Hospital of TCM, Nanjing, P.R. China; \\ ${ }^{3}$ AntiCancer, Inc., San Diego, CA, U.S.A.; \\ ${ }^{4}$ Department of Surgery, University of California, San Diego, CA, U.S.A.
}

\begin{abstract}
Background/Aim: The aim of the present study was to investigate the efficacy of an ethanolic extract of gamboge (EEG), a traditional Chinese medicine (TCM), both in vitro on colon cancer cells and in vivo in an orthotopic mouse model of human colon cancer. Materials and Methods: The in vitro cytotoxicity of EEG on colon cancer cells was determined with the CCK8 proliferation assay and the Annexin V-PE/7-AAD apoptosis assay. Efficacy of EEG in vivo was evaluated in an orthotopic mouse model of human colon cancer implated with the green fluorescent protein-expressing human colon cancer cell line SW480GFP. The tumor-bearing mice were treated with vehicle $(0.2$ $\mathrm{ml} /$ dose normal saline, po, daily), irinotecan (50 $\mathrm{mg} / \mathrm{kg} /$ dose, ip, twice a week), 5-FU (15 mg/kg/dose, ip, every other day) as positive controls or EEG at doses of 12.5, 25 and 50 $\mathrm{mg} / \mathrm{kg} /$ dose, po, daily. Real-time fluorescence imaging was performed to determine tumor inhibition in each treated group compared to the untreated controls. The protein expression of $\beta$-catenin, MMP-7, cyclin D1 and E-cadherin in the tumors was analyzed by immunohistochemistry. Results: EEG significantly induced proliferation inhibition and apoptosis of SW480 colon cancer cells in vitro in a dosedependent manner. Tumor growth in the colon-cancer orthotopic model was significantly inhibited by irinotecan, 5-FU and all three doses of EEG. The efficacy of EEG was comparable to irinotecan and 5-FU. Irinotecan, 5-FU and
\end{abstract}

*These Authors contributed equally to this study.

Correspondence to: Yunfei Gu, Nanjing University of Chinese Medicine, Nanjing, Jiangsu Province, P.R. China. Tel: +86 2586617141, Fax: +86 2586617141, e-mail: guyunfei127@126.com

Key Words: Gamboge, anti-tumor, Wnt/beta-catenin, colon cancer.
$50 \mathrm{mg} / \mathrm{kg}$ EEG significantly decreased the protein expression of $\beta$-catenin and MMP-7. Cyclin DI expression was decreased and E-cadherin expression was increased by irinotecan, 5-FU and all three doses of EEG. Conclusion: The present study demonstrates anti-tumor efficacy of EEG on colon cancer both in vitro and in vivo through inducing proliferation inhibition and apoptosis of SW480 colon cancer cells and inhibiting tumor growth, respectively. EEG exerts anti-tumor activity at least partly via down-regulation of the Wnt/ $\beta$-catenin signaling pathway.

Colon cancer is a leading cause of cancer and cancer-death worldwide $(1,2)$. Standard chemotherapy has had limited efficacy in this disease $(3,4)$. Traditional Chinese medicine (TCM) offers an opportunity to improve outcomes in colon and other cancers $(5,6)$.

Garcinia hanburyi Hook.f., a plant belonging to the Guttiferae family, grows in southeastern Asia. Its resin is used as a dye and folk medicine for its potent purgative effects, and in the treatment of infected wounds $(7,8)$. Many extracts from plants of this family have been proven to possess anti-tumor activities (9-11). Gamboge, the yellow gum-resin secreted in latex-tubes (ducts) in the middle bark of Garcinia hanburyi, is used externally for infected wounds and systemically for pain and edema (12).

However, the anti-tumor efficacy of gamboges has not been investigated. Several solvents e.g. hexane, chloroform, ethyl acetate etc. were used for extracting gamboge. Ethyl acetate was found to be the best solvent to yield a relatively pure extract and also high crude yield.

The purpose of the present study was to evaluate the anti-tumor efficacy of an ethanolic extract of gamboge (EEG) from Garcinia hanburyi Hook.f. in an orthotopic mouse model of human colon cancer. Possible mechanisms of action were also examined. 


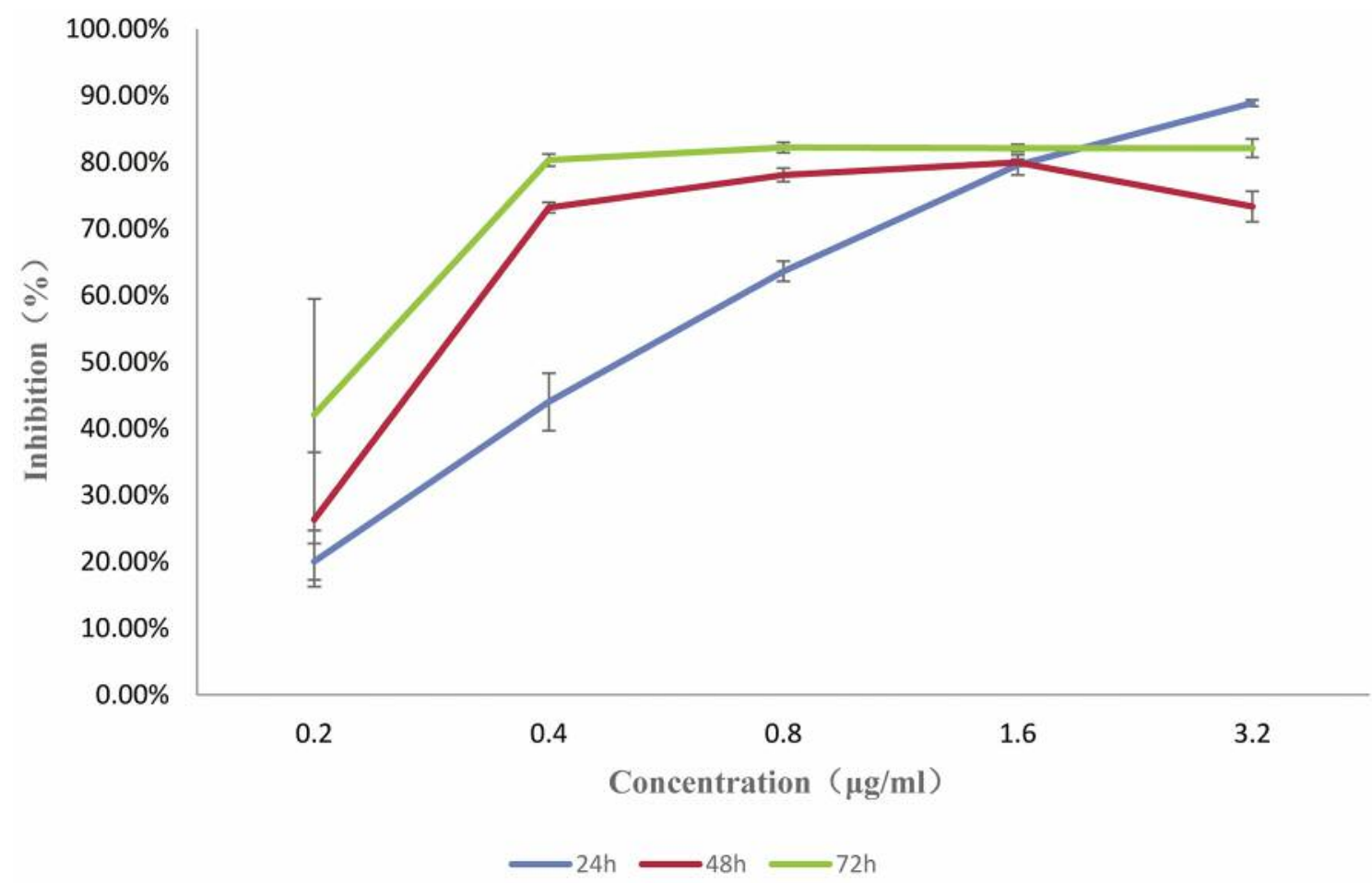

Figure 1. Efficacy of EEG on proliferation of colon cancer cells in vitro. Cell proliferation was measured using the CCK8 assay. Dose response curves of the EEG on colon cancer SW480 cells were constructed at concentrations of 0.2-3.2 $\mu \mathrm{g} / \mathrm{ml}$ at $24 \mathrm{~h}, 48 \mathrm{~h}$ and $72 \mathrm{~h}$.

\section{Materials and Methods}

Cell culture. The human colon cancer cell line SW480-GFP was obtained from AntiCancer, Inc., (San Diego, CA, USA). Cells were cultured in RPMI 1640 (GIBCO-BRL, Grand Island, New York, NY, USA) supplemented with $10 \%$ heat-inactivated fetal bovine serum (FBS, Hyclone, Logan, UT, USA) at $37^{\circ} \mathrm{C}$ in $5 \% \mathrm{CO}_{2}$ saturated humidity. All media were supplemented with penicillin/streptomycin (GIBCO-BRL, Grand Island, New York, NY, USA).

Test agents. 5-fluorouracil (5-FU) and irinotecan (IRN) were used in this study. Ethanolic extract of gamboge (EEG) was supplied by Jiangsu Hospital of Traditional Chinese Medicine (Nanjing, P.R. China).

Cell proliferation assay. Cell proliferation was measured with the CCK8 assay. SW480-GFP cells $\left(5 \times 10^{3}\right.$ cells/well $)$ were allowed to grow in 96-well overnight. Before treatment, all cells were switched to serum-free media with $1 \%$ BSA. Cells were then treated with EEG $(0.2,0.4,0.8,1.6,3.2 \mu \mathrm{g} / \mathrm{ml})$. After 24,48 and $72 \mathrm{~h}$ treatment, $10 \mu \mathrm{l}$ CCK8 reagent was added to each well for $4 \mathrm{~h}$. The optical density (OD) at $450 \mathrm{~nm}$ was determined with a microplate reader (Bio-Rad, CA, USA). The results are presented as a percentage inhibition relative to the negative control. The median inhibitory concentration $\left(\mathrm{IC}_{50}\right)$ was calculated from the dose-response curves. All experiments were repeated at least three times.
Detection of apoptotic cells. Apoptotic cells were identified with Annexin V-PE/7-AAD. Cells were seeded in 6 -well plates $\left(5 \times 10^{5}\right.$ cells/well) and divided into four groups: untreated control, EEG $0.25,0.5$ and $1.0 \mu \mathrm{g} / \mathrm{ml}$. After attachment to the dish, the cells in each group were treated with EEG and cultured for 24h. Cells were digested with $0.25 \%$ trypsin without EDTA (Thermo Fisher Scientific, CA, USA) and then were stained with the Annexin VPE/7-AAD apoptosis kit (Nanjing KeyGen BioTech, Nanjing, P.R.China) according to the manufacturer's instructions. Stained cells were identified and analyzed using flow cytometry (Becton Dickinson, NJ, USA). Each experiment was performed in triplicate.

Animal care. BALB/C male nude mice (48), aged 4-6 weeks, 20-25 $\mathrm{g}$, were purchased from Nanjing Biomedical Research Institute of Nanjing University (Nanjing, P.R.China). All mice were maintained in a HEPA-filtered environment at $24-25^{\circ} \mathrm{C}$. Humidity was maintained at $50-60 \%$. All animals were fed with autoclaved laboratory rodent diet. Animal experiments were approved by the Animal Committee of Nanjing Origin Biosciences, P.R.China (OB1617).

Orthotopic mouse model of colon cancer. The surgical orthotopic implantation (SOI) method followed published procedures $(13,14)$. Stocks of SW480-GFP tumors were established by subcutaneously injecting SW480-GFP cells $\left(5 \times 10^{6}\right)$ in the flank of nude mice. Colon tumors, grown s.c. in nude mice, were harvested at the exponential growth phase and resected under aseptic conditions. 
A

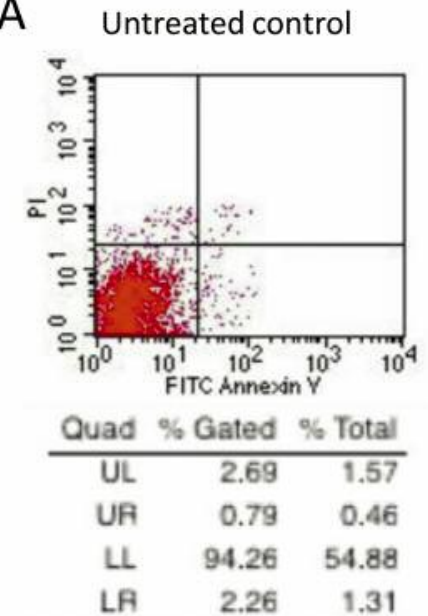

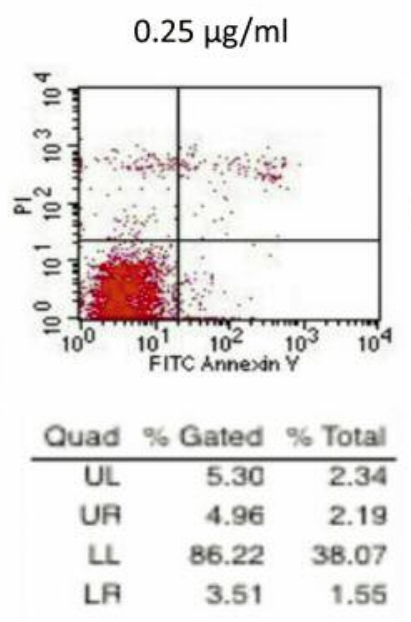
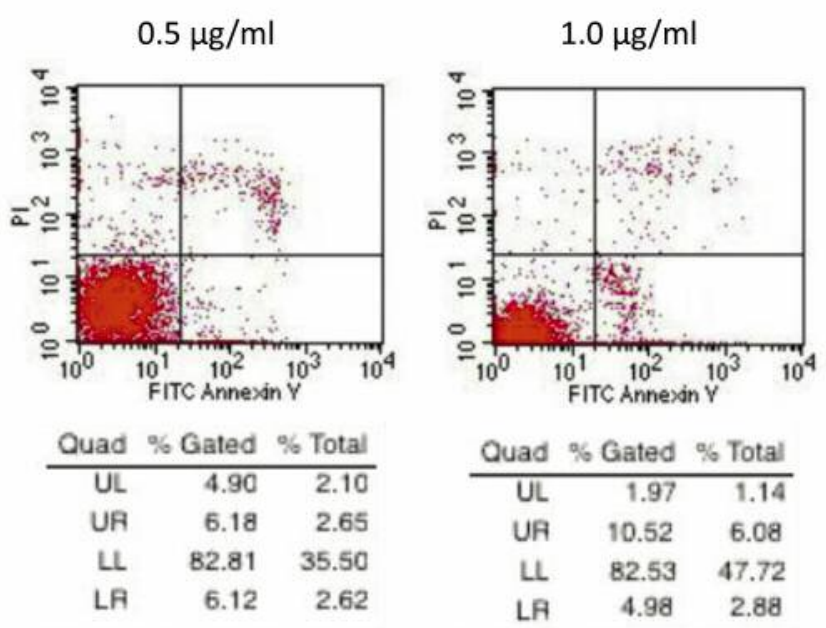

B

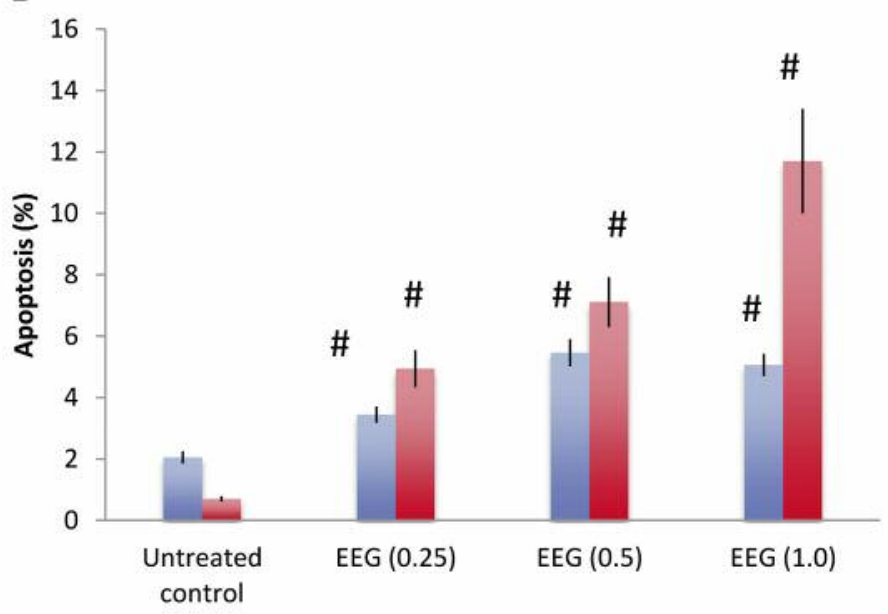

Concentration $(\mu \mathrm{g} / \mathrm{ml})$

Early apoptosis = Late-stage apoptosis

Figure 2. Efficacy of EEG on apoptosis of colon cancer cells in vitro. Apoptosis of colon cancer SW480 cells treated with EEG at concentrations of $0.25,0.5$ and $1 \mu \mathrm{g} / \mathrm{ml}$ was determined with Annexin V-PE/7-AAD staining and flow cytometry. A. Apoptosis analysis by flow cytometry. B. Comparison of early and latestage apoptosis. ${ }^{\#} p<0.01$ when compared with untreated control.

Strong GFP expression of the SW480-GFP tumor tissue was confirmed by fluorescence microscopy. Necrotic tissues were removed and viable tissues were cut with scissors and minced into $1 \mathrm{~mm}^{3}$ pieces. Animals were anesthetized by injection of a $0.02 \mathrm{ml}$ solution of $50 \%$ ketamine, $38 \%$ xylazine, and $12 \%$ acepromazine maleate. After proper exposure of the colon following a lowermidline abdominal incision, the serosa of the colon was removed and two $1 \mathrm{~mm}^{3}$ tumor fragments per mouse were implanted on the wall of the colon with an 8-0 surgical suture. The intestine was then returned to the abdominal cavity. The incision in the abdominal wall was closed with a 6-0 surgical suture in one layer. All procedures of the operation described above were performed under an $8 \mathrm{x}$ magnification microscope (Shanghai Precision Instruments, YZ20P5, Shanghai, P.R. China).

Treatment. Treatments were initiated when mean tumor volume reached $100 \mathrm{~mm}^{3}$. The mice were randomly divided into six groups of eight. Group 1 (vehicle control) received saline by oral gavage daily at $0.2 \mathrm{ml} /$ dose for four weeks. Group 2 (IRN) received intraperitoneal irinotecan twice a week at $50 \mathrm{mg} / \mathrm{kg} / \mathrm{dose}$ for four weeks. Group 3 (5-fluorouracil [5-FU]) received intraperitoneal 5FU every other day at $15 \mathrm{mg} / \mathrm{kg} /$ dose for two weeks. Group 4-6 received EEG by oral gavage daily for four weeks at 12.5, 25 and $50 \mathrm{mg} / \mathrm{kg} / \mathrm{dose}$, respectively. Tumor growth was measured by whole-body fluorescence imaging with a fluorescence stereo microscope (MZ650; Nanjing Optic Instrument Inc., Nanjing, P.R. China) equipped with band-pass HQ600/50 emission and HQ540/40 excitation filters (Chroma Technology, Brattleboro, VT, USA). Animal body weights and clinical signs were recorded over the course of the experiments. All animals were sacrificed 28 days after initial treatment. At autopsy open fluorescence imaging was performed and then the tumor was removed and weighed. Images were processed and analyzed with the use of IMAGE PRO Plus 6.0 software (Media Cybernetics, Silver Spring, MD, USA). 
A
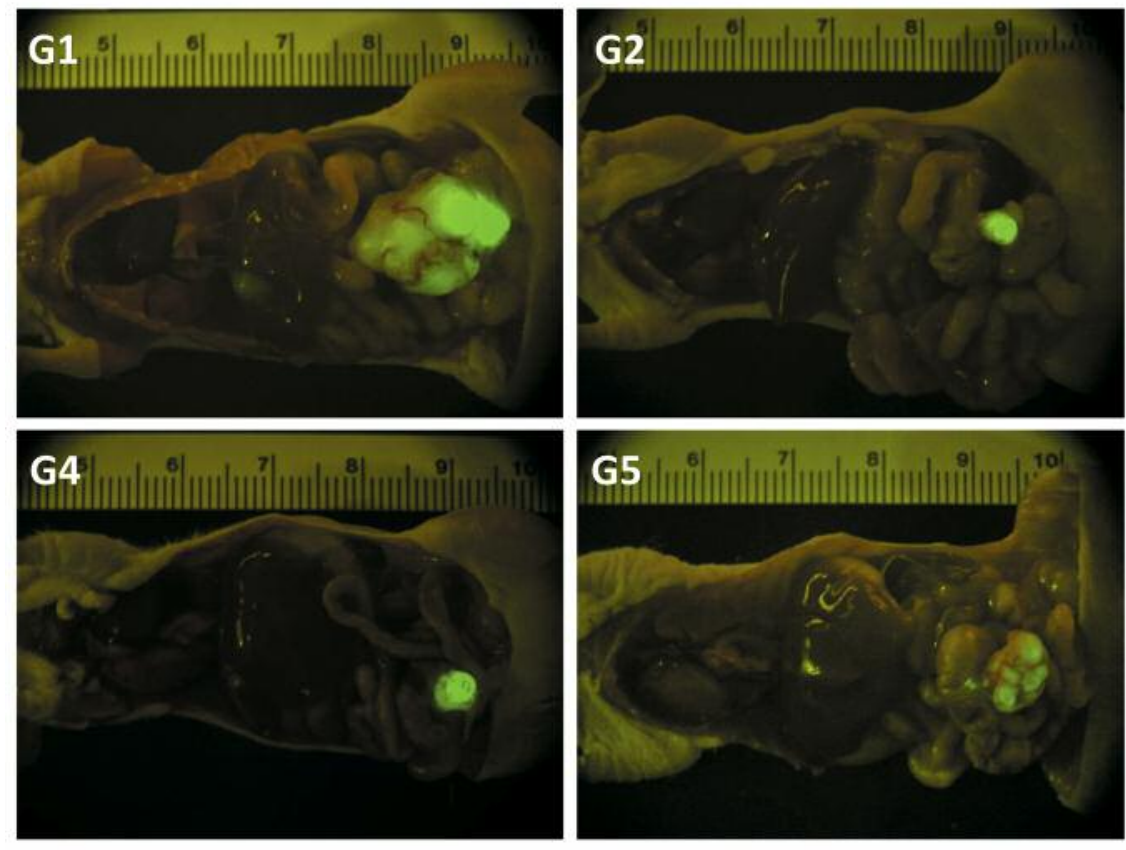

B

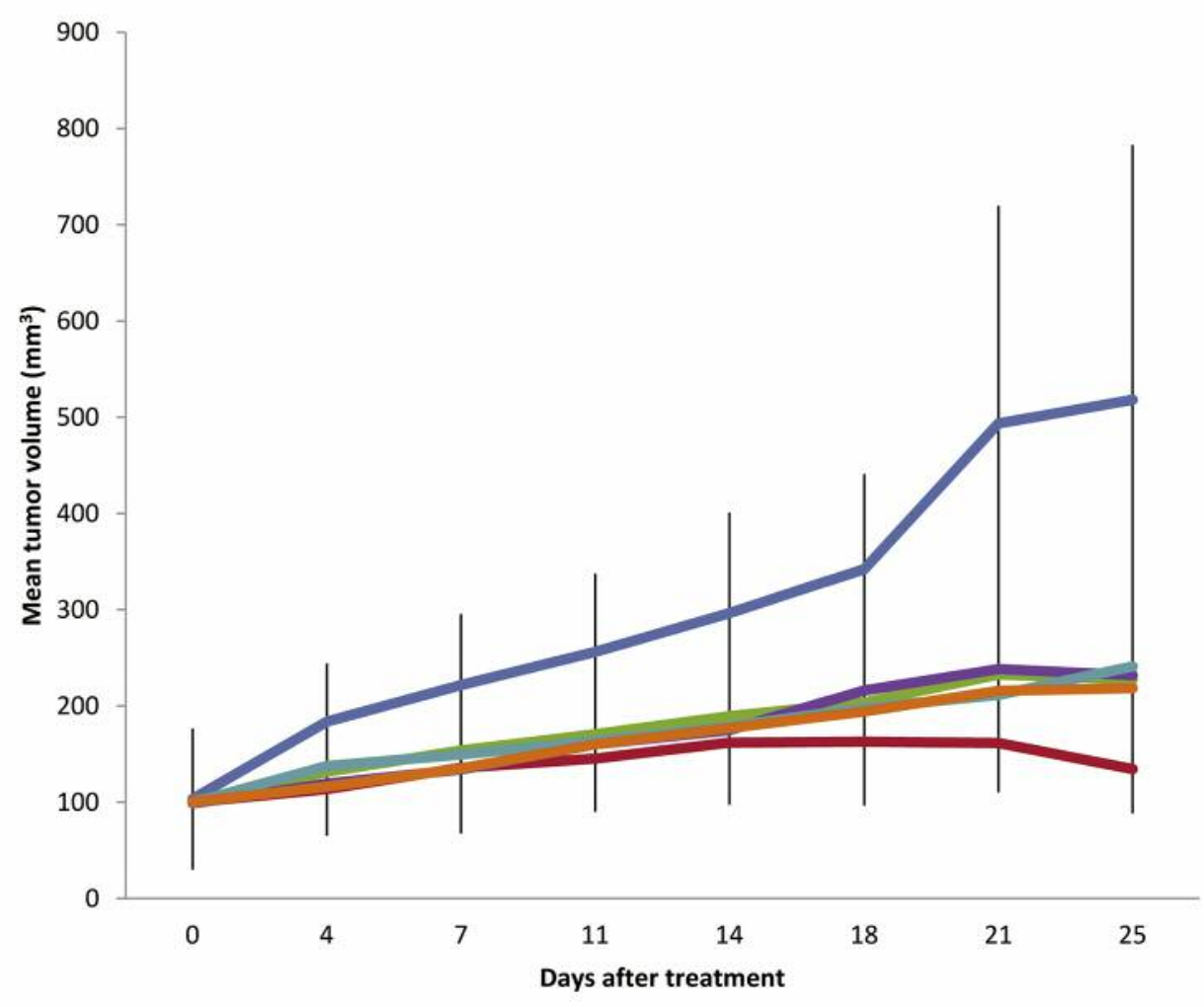

Figure 3. Continued 


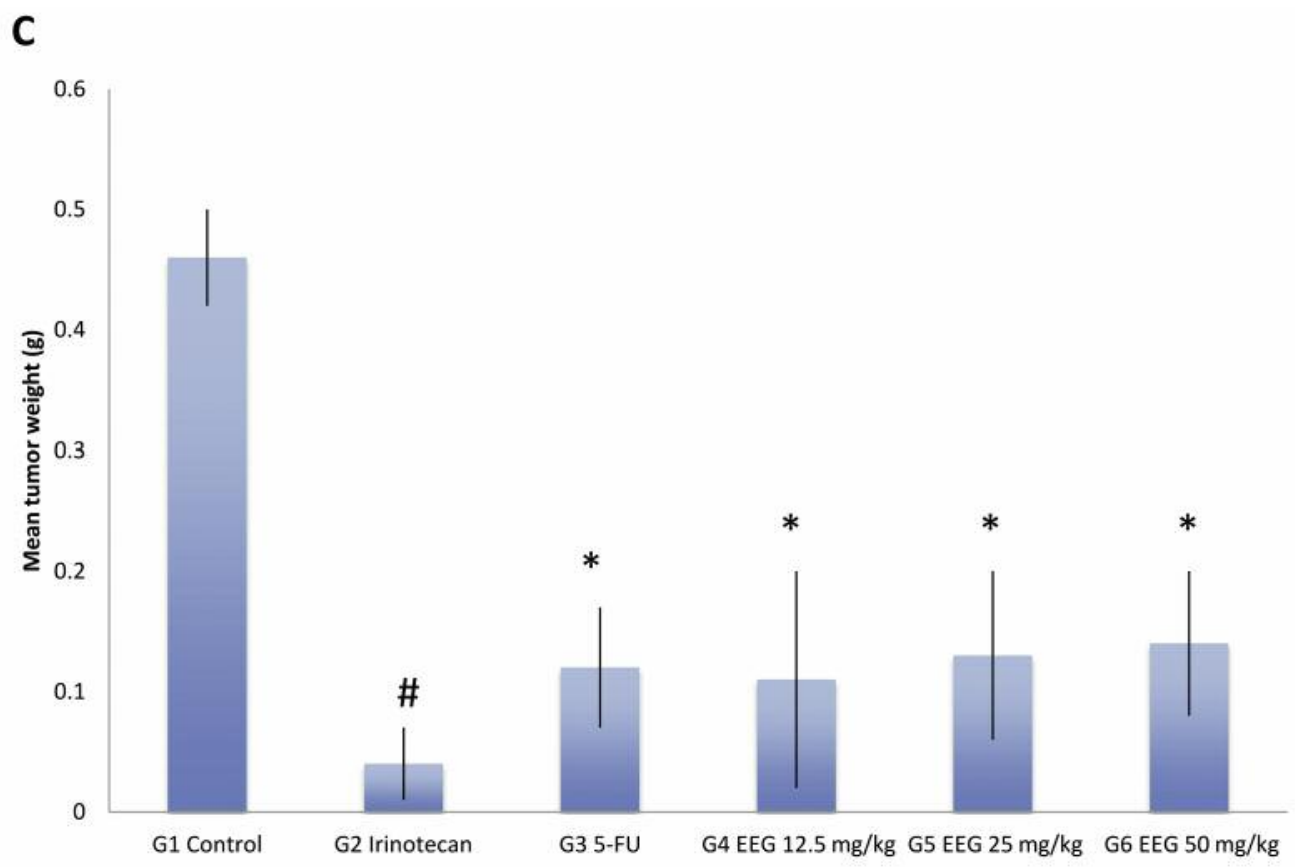

Figure 3. Efficacy of EEG on tumor growth in an orthotopic mouse model of SW480 colon cancer. Tumor growth was monitored and quantified by real-time whole-body fluorescence imaging. Tumors were resected at necropsy and final tumor weights determined. A: Representative fluorescence imaging of tumors for each group at the end of the study. B: Tumor growth curves for each treatment group. C: Final tumor weights from each treatment group. ${ }^{*} p<0.05,{ }^{*} p<0.01$ when compared with the control.

Immunohistochemistry. At the end of the study, all mice were sacrificed and the tumors were removed and weighed. Tumor tissues were fixed in $10 \%$ buffered formalin and paraffin-embedded. For immunohistochemistry, sections were incubated with primary antibodies against $\beta$-catenin, MMP-7, cyclin D1 and E-cadherin (BD Biosciences, San Diego, CA, USA) overnight at $4^{\circ} \mathrm{C}$ after permeabilization with a solution of $0.1 \%$ sodium citrate and $0.1 \%$. Triton X-100 and blocking with $10 \%$ rabbit serum. After washing with $\mathrm{pH} 7.4$ phosphate-buffered saline (PBS), the sections were then incubated with secondary antibody (Dako REAL EnVision Detection System, Dako, UK) for $30 \mathrm{~min}$ at room temperature. Color development was performed with 3, 3'-diaminobenzidine (DAB). Nuclei were lightly counter stained with hematoxylin. The slides were viewed at $\times 400$ magnification and positive cells were recognized by the appearance of brown staining. The expression level was quantified by the average optical density (AOD) of the positive cells in five fields per sample with ImagePro Plus 6.0 software (Media Cybernetics, Silver Spring, MD, USA) (15).

Statistical analysis. Data are expressed as means $\pm \mathrm{SD}$, and were analyzed by one-way analysis of variance (ANOVA), using SPSS software version 16.0 , where $p<0.05$ is considered to be statistically significant.

\section{Results and Discussion}

EEG inhibits proliferation of colon cancer cells. EEG significantly inhibited SW480-GFP cell growth in a dose- and time-course-dependent manner (Figure 1). The $\mathrm{IC}_{50}$ values of EEG were $0.54 \mu \mathrm{g} / \mathrm{ml}$ at $24 \mathrm{~h}, 0.36 \mu \mathrm{g} / \mathrm{ml}$ at $48 \mathrm{~h}$ and 0.24 $\mu \mathrm{g} / \mathrm{ml}$ at $72 \mathrm{~h}$ of treatment.

EEG induces apoptosis in colon cancer cells. EEG at doses of $0.25,0.5$ and $1 \mu \mathrm{g} / \mathrm{ml}$ significantly increased the frequency of early and late-stage apoptotic SW480-GFP cells compared to the untreated cells. Late-stage apoptosis was induced by EEG in a dose-dependent manner (Figure 2).

EEG inhibits orthotopic SW480 tumor growth. Tumor growth was significantly inhibited in the mice treated with all three doses of EGG as well as with IRN and 5-FU compared to the control group from day 7 after treatment initiation $(p<0.05)$. Representative fluorescence images, tumor growth curves and final tumor weight in each group are shown in Figures $3 \mathrm{~A}, \mathrm{~B}$ and $\mathrm{C}$, respectively. The final tumor weight in the EEG-treated groups, as well as the IRN and 5-FU groups were also significantly reduced, compared to the control group $(p<0.05)$.

EEG modulates the Wnt/beta-catenin signaling pathway. EGG $(50 \mathrm{mg} / \mathrm{kg})$, irinotecan and 5-FU significantly decreased the protein expression levels of $\beta$-catenin and MMP-7 compared to the control group $(p<0.05)$ (Figure 4A, B). Cyclin D1 


\section{A}

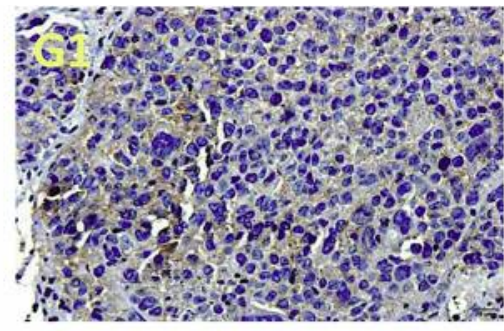

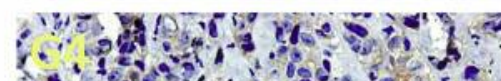
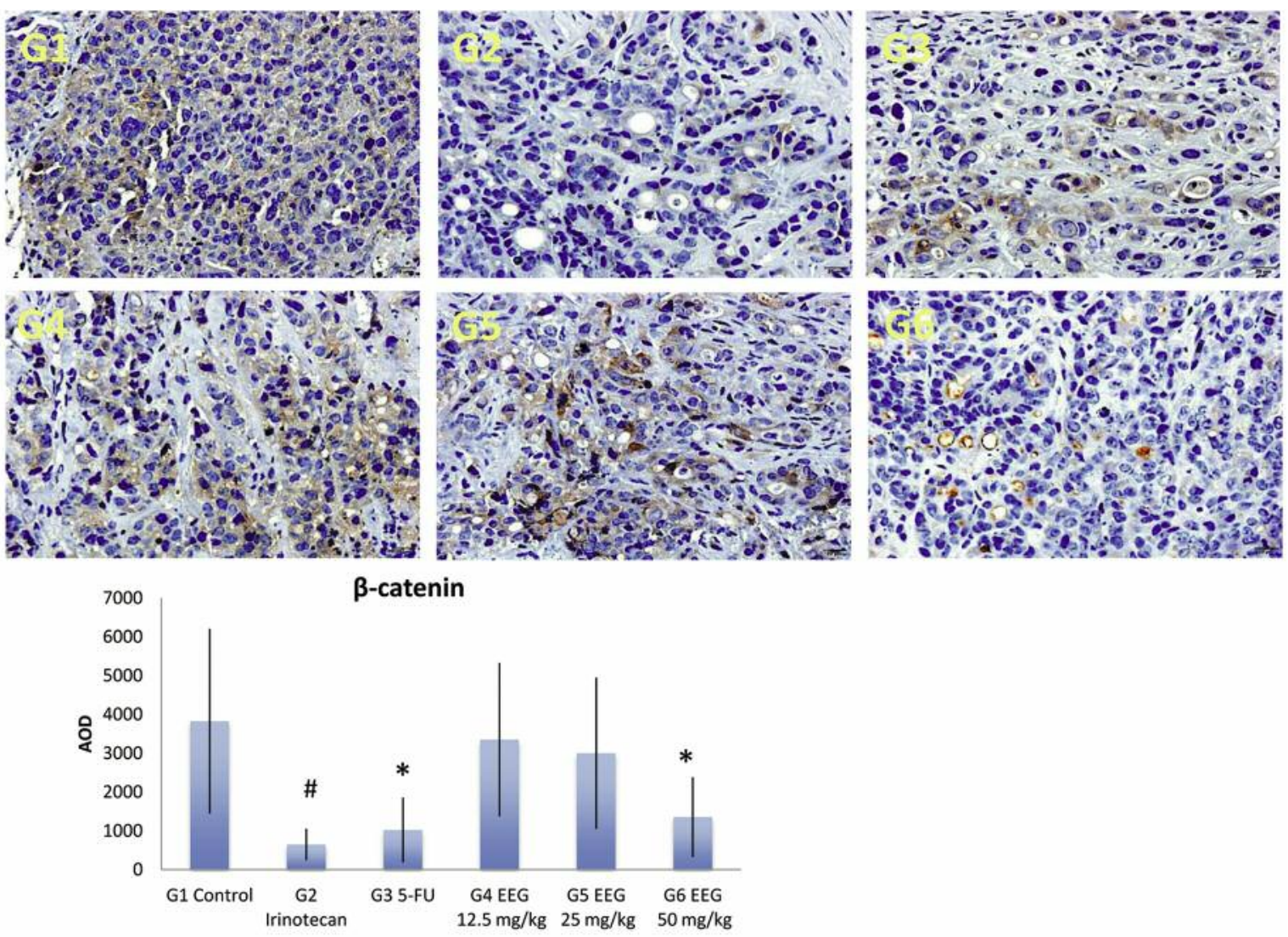

B
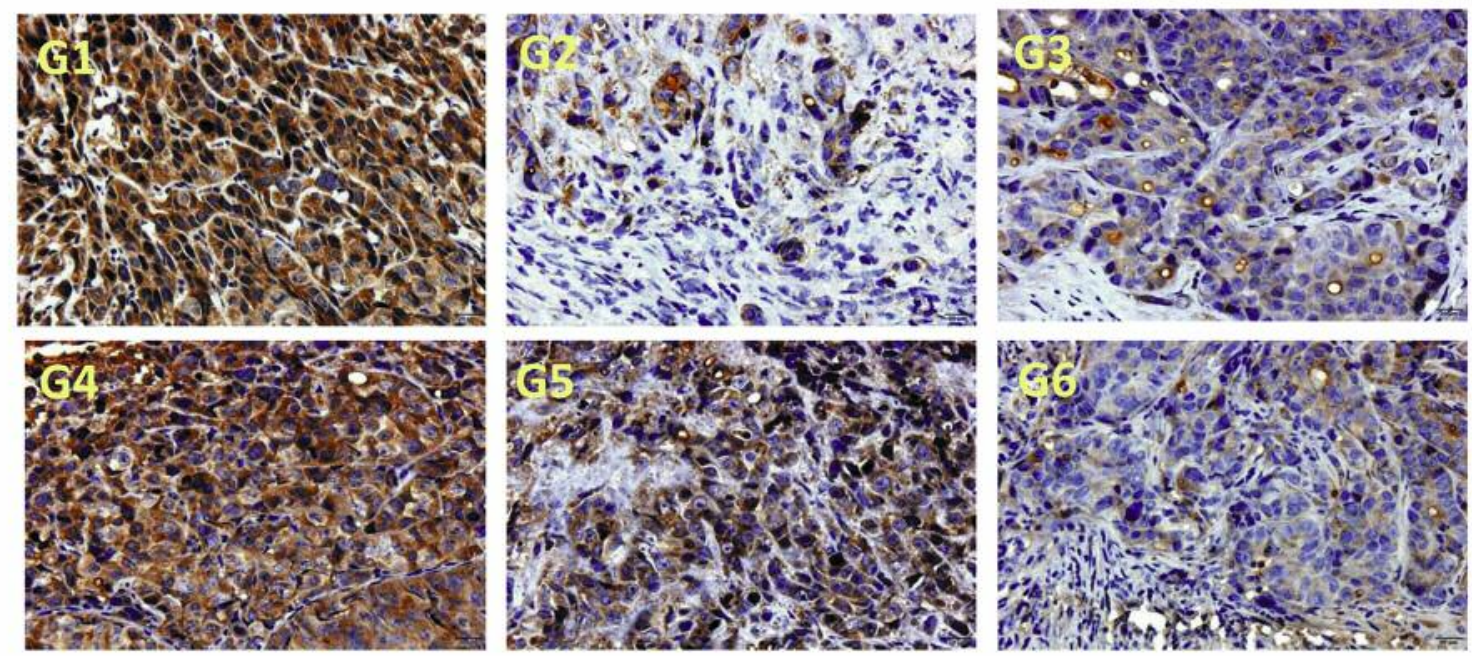

MMP-7

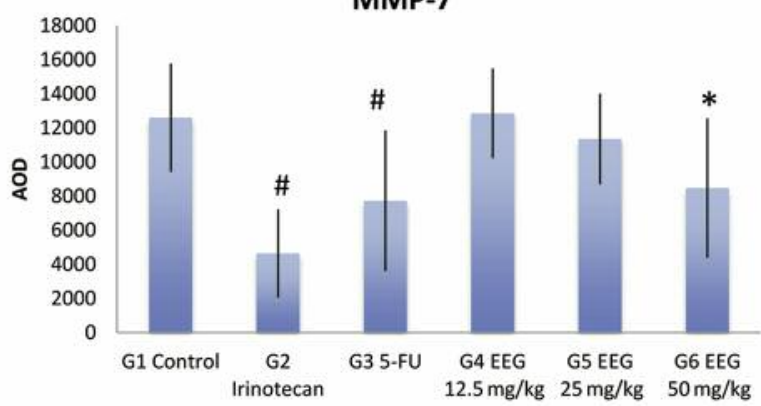

Figure 4. Continued 

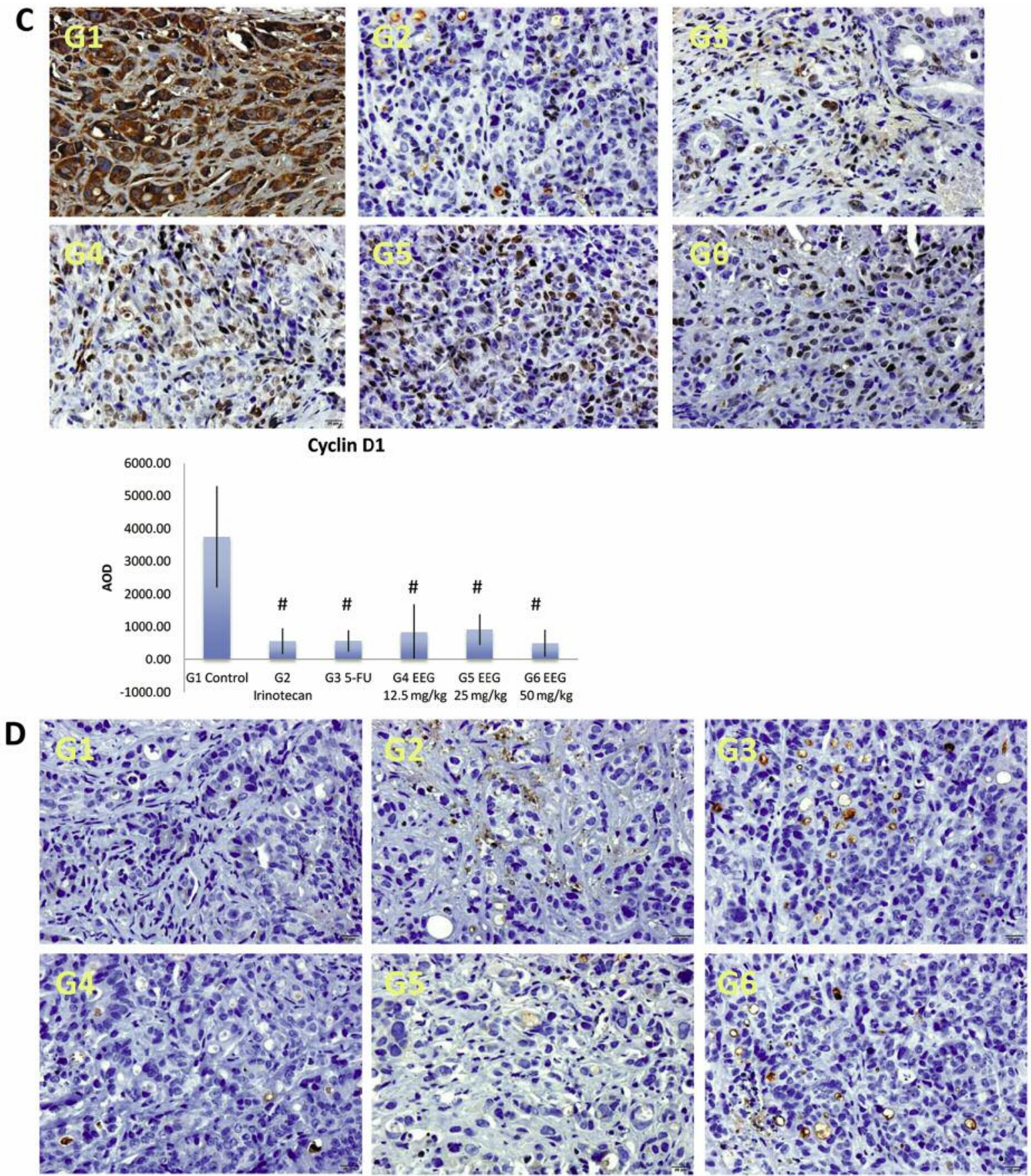

E-cadherin

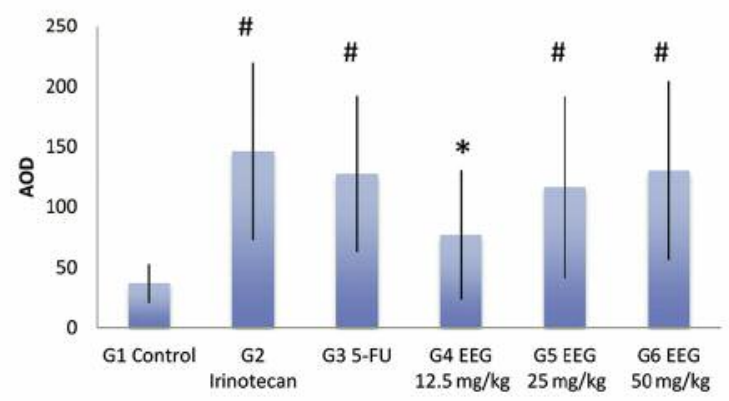

Figure 4. Efficacy of EEG on the Wnt/beta-catenin signaling pathway. Protein expression of $\beta$-catenin, cyclin D1, MMP7 and E-cadherin in the tumor tissue was analyzed with immunohistochemical staining. A-D: Representative immunohisto-chemical images and quantitation of the expression of $\beta$-catenin, MMP-7, cyclin D1 and E-cadherin from each treatment group. ${ }^{*} p<0.05,{ }^{*} p<0.01$, compared with the control. $\mathrm{AOD}=$ average optical density. 


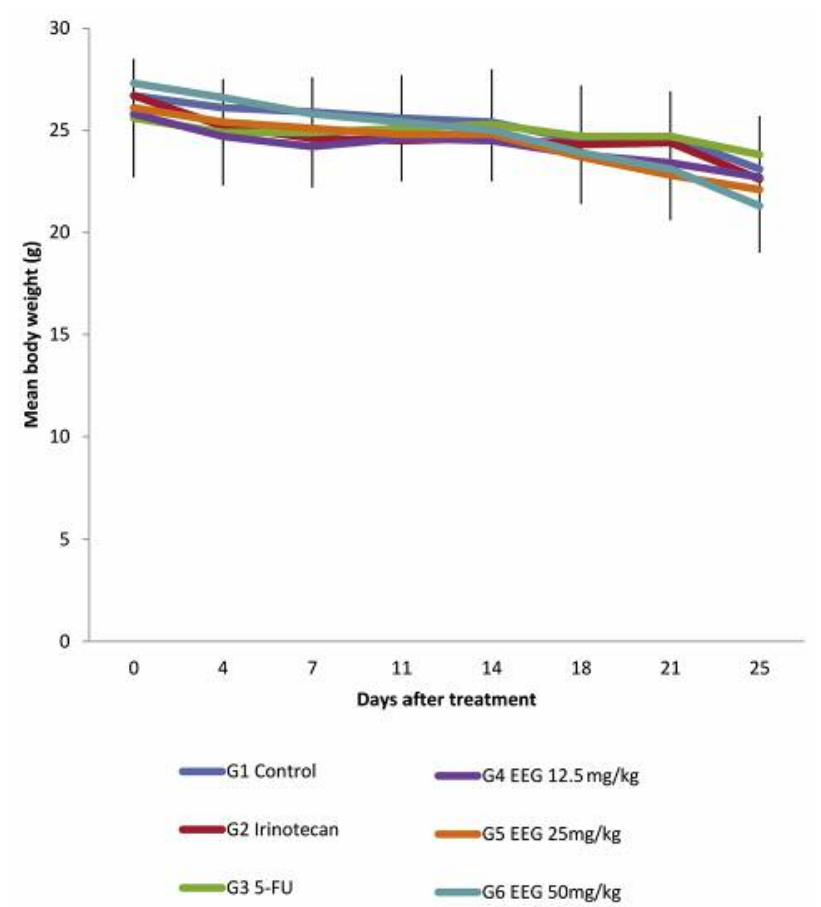

Figure 5. Effect of EEG on mouse body weight. Line graphs depict mouse body weight during the treatment period.

expression was significantly reduced in the groups treated with all three doses of EEG as well as in the IRN and 5-FU groups compared to the control group $(p<0.01)$ (Figure 4 C). All three doses of EEG as well as irinotecan and 5-FU increased protein expression of E-cadherin compared to control group $(p<0.01)$ (Figure 4D).

Body weight and toxicity. No physical or behavioral signs indicated adverse effects due to EEG, IRN or 5-FU. No significant body weight loss was found in any treated groups (Figure 5).

The present study is the first to demonstrate anti-tumor activity of EEG on human colon cancer. EEG inhibited cell proliferation of SW480 human colon cancer cells and induced apoptosis, suggesting that EEG exerted its antitumor activity through apoptosis. EEG significantly inhibited tumor growth in an orthotopic mouse model of SW480 colon cancer comparable to 5-FU and IRN, first-line therapy for this disease.

Immunohistochemical analysis showed that EEG inhibited Wnt signaling by down-regulating $\beta$-catenin which resulted in decreased transcription of the downstream genes of $\beta$-catenin, including cyclin D1 and MMP-7 (16-19). EEG treatment increased the protein-expression level of E-cadherin, a marker of epithelial cells which is involved in the epithelialmesenchymal transition $(20,21)$. Based on these findings, we infer that EEG exerts anti-tumor activity at least partly via down-regulation of the Wnt/ $\beta$-catenin signaling pathway.

In conclusion, the present study demonstrates the efficacy of EEG on colon cancer both in vitro and in vivo by inducing apoptosis of SW480 cells and inhibiting tumor growth via down-regulation of the $\mathrm{Wnt} / \beta$-catenin signaling pathway.

The orthotopic mouse tumor model, especially with the use of GFP for imaging, is revolutionizing the TCM field enabling discovery of potent anti-tumor and anti-metastatic agents $(15,22-30)$. The orthotopic model is the bridge to the clinic for TCM $(13,14,31)$.

\section{Conflicts of Interest}

None of the Authors have a conflict of interest in regard to this study.

\section{Acknowledgements}

This work was supported by the National Natural Science Foundation of China (Grant No. 81473565) and the Postgraduate Research \& Practice Innovation Program of Jiangsu Province.

\section{References}

1 Mone A, Mocharla R, Avery A and Francois F: Issues in Screening and Surveillance Colonoscopy, 2013. Available from: http://www.doc88.com/p-8052917955462.html.

2 Haggar FA and Boushey RP: Colorectal cancer epidemiology: incidence, mortality, survival, and risk factors. Clin Colon Rectal Surg 22: 191-197, 2009.

3 Van Cutsem E, Borràs JM, Castells A, Ciardiello F, Ducreux M, Haq A, Schmoll HJ and Tabernero J: Improving outcomes in colorectal cancer: where do we go from here? Euro J Cancer 49: 2476-2485, 2013.

4 Fleming M, Ravula S, Tatishchev SF and Wang HL: Colorectal carcinoma: pathologic aspects. J Gastrointest Oncol 3: 153-173, 2012.

5 Ling CQ, Yue XQ and Ling C: Three advantages of using traditional Chinese medicine to prevent and treat tumor. J Inte Med 12: 331-335, 2014.

6 Schwartsmann G, Ratain MJ, Cragg GM, Wong JE, Saijo N, Parkinson DR, Fujiwara Y, Pazdur R, Newman DJ, Dagher R and Di Leone L: Anticancer drug discovery and development throughout the world. J Clin Oncol 20: 47S-59S, 2002.

7 Sukpondma Y, Rukachaisirikui V and Phongpaichit S: Antibacterial caged-tetraprenylated xanthones from the fruits of Garcinia hanburyi. Chem Pharm Bull 53: 850-852, 2005.

8 Han QB, Wang, YL, Yang L, Tso TF, Qiao CF, Song JZ, Xu LJ, Chen SL, Yang DJ and Xu HX: Cytotoxic polyprenylated xanthones from the resin of Garcinia hanburyi. Chem Pharm Bull 54: 265-267, 2006.

9 Wu ZQ, Guo QL, You QD, Zhao L and Gu HY: Gambogic acid inhibits proliferation of human lung carcinoma SPC-A1 cells in vivo and in vitro and represses telomerase activity and telomerase reverse transcriptase mRNA expression in the cells. Biol Pharm Bull 27: 1769-1774, 2004. 
10 Zhao L, Guo QL, You QD, Wu ZQ and Gu HY: Gambogic acid Induces apoptosis and regulates expressions of $\mathrm{Bax}$ and $\mathrm{Bcl}-2$ protein in human gastric carcinoma MGC-803 cells. Biol Pharm Bull 27: 998-1003, 2004.

11 Guo QL, Lin SS, You QD, Gu HY, Yu J, Zhao L, Qi Q, Liang $\mathrm{F}$, Tan $\mathrm{Z}$ and Wang $\mathrm{X}$ : Inhibition of human telomerase reverse Transcriptase gene expression by gambogic acid in human hepatoma SMMC-7721 cells. Life Sci 78: 1238-1245, 2006.

12 Panthong A, Norkaew P, Kanjanapothi D, Taesotikul T, Anantachoke N and Reutrakul V: Anti-inflammatory, analgesic and antipyretic activities of the extract of gamboges from Garcinia hanburyi Hook f. J Ethnopharmacol 111: 335-340, 2007.

13 Hoffman RM: Orthotopic metastatic mouse models for anticancer drug discovery and evaluation: a bridge to the clinic. Investigational New Drugs 17: 343-359, 1999.

$14 \mathrm{Fu}$ X, Besterman JM, Monosov A and Hoffman RM: Models of human metastatic colon cancer in nude mice orthotopically constructed by using histologically intact patient specimens. Proc Natl Acad Sci USA 88: 9345-9349, 1991.

15 Xu X, Li X, Zhang L, Liu Z, Pan Y, Chen D, Bin D, Deng Q, Sun YU, Hoffman RM, Yang Z, and Yuan H: Enhancement of wound healing by the traditional Chinese medicine herbal mixture Sophora Flavescens in a rat model of perianal ulceration. In Vivo 31: 543-549, 2017.

16 Park SJ, Ahmad F, Philp A, Baar K, Williams T and Luo H: Resveratrol ameliorates aging-related metabolic phenotypes by inhibiting cAMP phosphodiesterases. Cell 148: 421-433, 2012.

17 Moradi A, Ghasemi F, Anvar, K, Hassanian SM, Simab SA and Ebrahimi S: The cross-regulation between SOX15 and Wnt signaling pathway. J Cell Physiol 232: 3221-3225, 2017.

18 Clevers $\mathrm{H}$ : Wnt/beta-catenin signaling in development and disease. Cell 127: 469-480, 2006.

19 Anastas JN and Moon RT: WNT signalling pathways as therapeutic targets in cancer. Nat Rev Cancer 13: 11-26, 2013.

20 Shan S, Lv Q, Zhao Y, Liu C, Sun Y, Xi K, Xiao J and Li C: $\mathrm{Wnt} /$ beta-catenin pathway is required for epithelial to mesenchymal transition in CXCL12 over ex-pressed breast cancer cells. Int J Clin Exp Pathol 8: 12357-12367, 2015.

21 Mao XW, Xiao JQ, Xu G, Li ZY Wu HF, Li Y, Zheng YC and Zhang N: CUL4B promotes bladder cancer metastasis and induces epithelial-to-mesenchymal transition by activating the $\mathrm{Wnt} / \beta$ catenin signaling pathway. Oncotarget 8: 77241-77253, 2017.

22 Wang M, Zhang X, Xiong X, Yang Z, Sun Y, Yang Z, Hoffman RM and Liu Y: Efficacy of the Chinese Traditional Medicinal Herb Celastrus orbiculatus Thunb on human hepatocellular carcinoma in an orthotopic fluorescent nude mouse model. Anticancer Res 32: 1213-1220, 2012.

$23 \mathrm{Hu}$ M, Zhao M, An C, Yang M, Zhang Y, Suetsugu A, Tome Y, Yano S, Fu Y, Hoffman RM and Hu K: Real-time imaging of induction of apoptosis of human breast cancer cells by the traditional Chinese medicine herb Tubeimu. Anticancer Res 32: 2509-2514, 2012.
24 Zhang Y, Zhang N, Su S, Hoffman RM and Zhao M: Salmonella typhimurium A1-R tumor targeting in immunocompetent mice is enhanced by a Traditional Chinese Medicine herbal mixture. Anticancer Res 33: 1837-1843, 2013.

25 Zhang L, Wu C, Zhang Y, Liu F, Zhao M, Bouvet M and Hoffman RM: Efficacy comparison of traditional Chinese medicine LQ versus gemcitabine in a mouse model of pancreatic cancer. J Cell Biochem 114: 2131-2137, 2013.

26 Zhang L, Wu C, Zhang Y, Liu F, Wang X, Zhao M and Hoffman RM: Comparison of efficacy and toxicity of Traditional Chinese Medicine (TCM) herbal mixture LQ and conventional chemotherapy on lung cancer metastasis and survival in mouse models. PLoS One 9: e109814, 2014.

27 Zhang L, Wu C, Bouvet M, Yano S and Hoffman RM: Traditional Chinese medicine herbal mixture LQ arrests FUCCIexpressing $\mathrm{HeLa}$ cells in $\mathrm{G}_{0} / \mathrm{G}_{1}$ phase in $2 \mathrm{D}$ plastic, $2.5 \mathrm{D}$ Matrigel ${ }^{\circledR}$, and 3D Gelfoam ${ }^{\circledR}$ culture visualized with FUCCI imaging. Oncotarget 6: 5292-5298, 2015.

28 Yin G, Tang D, Dai J, Liu M, Wu M, Sun Y, Yang Z, Hoffman RM, Li L, Zhang S and Guo X: Combination efficacy of Astragalus membranaceus and Curcuma wenyujin at different stages of tumor progression in an orthotopic nude mouse model of metastatic human ovarian cancer. Anticancer Res 35: 31933208, 2015.

29 Dai X, Liu D, Liu M, Zhang X, Wang W, Jin F, Qian Y, Wang X, Zhao J, Wu Y, Xiong F, Chang N, Sun Y, Yang Z, Hoffman RM and Liu Y: Anti-metastatic efficacy of traditional Chinese medicine (TCM) ginsenoside conjugated to an VEFGR-3 antibody on human gastric cancer in an orthotopic mouse model. Anticancer Res 37: 979-986, 2017.

30 Yang G, Qiu J, Wang D, Tao Y, Song Y, Wang H, Tang J, Wang $X$, Sun Y, Yang $Z$ and Hoffman RM: Traditional Chinese medicine curcumin sensitizes human colon cancer to radiation by altering the expression of DNA repair-related genes. Anticancer Res 38: 131-136, 2018.

31 Glinskii AB, Smith BA, Jiang P, Li X-M, Yang M, Hoffman RM and Glinsky GV: Viable circulating metastatic cells produced in orthotopic but no ectopic prostate cancer models. Cancer Res 6 : 4239-4243, 2003.
Received January 16, 2018

Revised February 8, 2018

Accepted February 9, 2018 